\title{
3D models related to the publication: One skull to rule them all? Descriptive and comparative anatomy of the masticatory apparatus in five mice species based on traditional and digital dissections.
}

\author{
Ginot Samuel ${ }^{1 *}$, Claude Julien², Hautier Lionel ${ }^{2}$ \\ ${ }^{1}$ Institut de Génomique Fonctionnelle de Lyon - UMR 5242, ENS Lyon, Lyon, France \\ ${ }^{2}$ Institut des Sciences de l'Evolution de Montpellier, Université de Montpellier, CNRS, IRD, Cc 064; place Eugène Bataillon, 34095 Montpellier \\ Cedex 5, France. \\ *Corresponding author: samuel.ginot@ens-lyon.fr
}

\begin{abstract}
The present 3D Dataset contains the 3D models analyzed in the article entitled "One skull to rule them all? Descriptive and comparative anatomy of the masticatory apparatus in five mice species based on traditional and digital dissections" (Ginot et al., Journal of Morphology, https://doi.org/10.1002/jmor.20845).
\end{abstract}

Keywords: Dissection, iodine-enhanced CT-scan, Masticatory musculature, Murinae, skull myology

Submitted:2018-04-19, published online:2018-09-04. https://doi.org/10.18563/journal.m3.65

\section{INTRODUCTION}

These 3D models represent the skulls of five different species of mice, some captured in the wild, others raised in the lab, but descending from wild ancestors. The species represented are the following : Mus caroli, Mus cervicolor, Mus fragilicauda, Mus minutoides, and Mus pahari (see Table 1 and Figure 1). Mus minutoides was raised in the lab in the facilities of the Université de Montpellier, while other specimens were captured during fieldwork in Thailand. The goal of the study in which these skulls are included was to improve our knowledge regarding the anatomical variation of the masticatory musculature in murine rodents, particularly in the genus Mus, which was so far limited to laboratory strains of M. musculus. The masticatory muscles of our sample of mice species were compared with each other, as well as with other murine rodent species described in the literature. To do so, we combined traditional dissections and descriptions with iodine-enhanced CT-scan reconstructions. Although the arrangements of the masticatory muscles appeared fairly similar between species, unexpected differences were highlighted, possibly linked with functional and ecological differences.

\section{METHODS}

The 3D models presented were obtained by a four-step process. First, the skulls, kept in $70 \%$ ethanol, were manually dissected on one side. Then, we ran a first scan on each specimen so the bones could be more easily reconstructed and distinguished from soft tissue. Third, the skulls were stained with iodine, following the protocol described in Cox and Jeffery (2011) and Baverstock et al. (2013): we fixed the heads in a $4 \%$ formaldehyde solution, and placed them in a $3.75 \%$

\begin{tabular}{|c|c|c|}
\hline Model IDs & Taxon & Description \\
\hline R7314 & Mus cervicolor & $\begin{array}{l}\text { Skull with associated } \\
\text { masticatory muscles. }\end{array}$ \\
\hline R7264 & Mus caroli & $\begin{array}{l}\text { Skull with associated } \\
\text { masticatory muscles }\end{array}$ \\
\hline R7260 & Mus fragilicauda & $\begin{array}{l}\text { Skull with associated } \\
\text { masticatory muscles }\end{array}$ \\
\hline R7226 & Mus pahari & $\begin{array}{l}\text { Skull with associated } \\
\text { masticatory muscles }\end{array}$ \\
\hline minutoides-1 & Mus minutoides & $\begin{array}{l}\text { Skull with associated } \\
\text { masticatory muscles }\end{array}$ \\
\hline
\end{tabular}

Table 1. Model list. Collection: Ceropath/BiodivehealthSEA

I2KI solution dissolved in 1x PBS (phosphate buffered saline). The specimens were left in this contrast agent for about 14 days (depending on the size and fixation of the skull), and were scanned again, making sure that no contrast agent could leak in the scanner. Finally, the cranium and mandible were extracted from the first scan within Avizo 9.2 using the threshold tool, while the muscles were reconstructed manually (also within Avizo 9.2) with the brush and interpolation tools. Muscles and bones reconstructed surfaces were aligned using the "Register" function in Avizo. The 3D surface models are provided in .ply format, and can therefore be opened with a wide range of freeware.

\section{ACKNOWLEDGEMENTS}

The authors are thankful to S. Morand and the BiodivhealthSEA program (ANR 11 CEPL 0002) who allowed us to participate in their fieldwork. We are also grateful F. Veyrunes who lended us the M. minutoides specimens. 


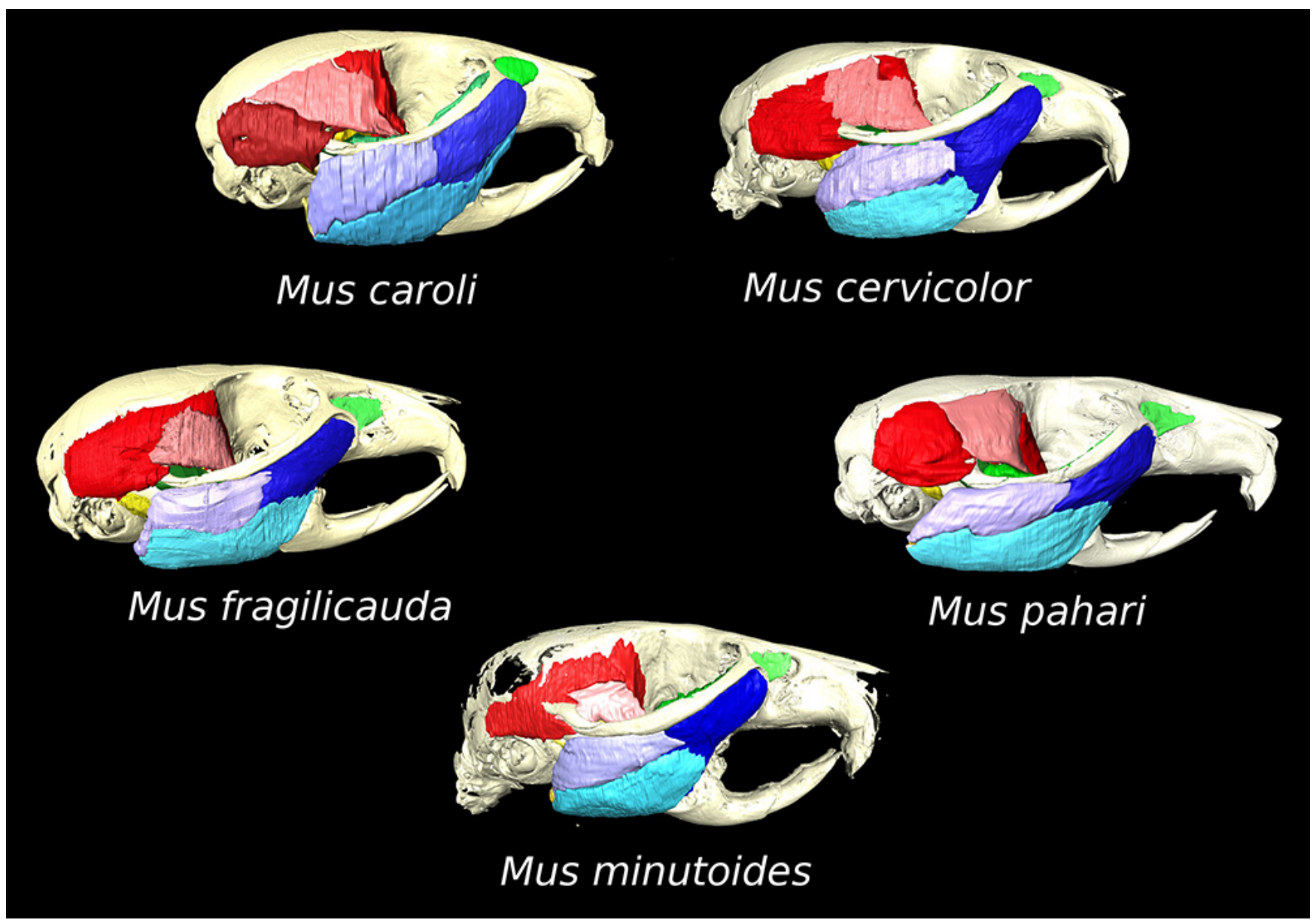

Figure 1. 3D reconstructions of the skulls of the five species of mice studied. 


\section{BIBLIOGRAPHY}

Baverstock, H., Jeffery, N. S., and Cobb, S. N. (2013). The morphology of the mouse masticatory musculature. Journal of Anatomy, 223(1), 46-60. https://doi.org/10.1111/joa.12059

Cox, P. G., and Jeffery, N. (2011). Reviewing the morphology of the jaw-closing musculature in squirrels, rats, and guinea pigs with contrast-enhanced microCT. The Anatomical Record, 294(6), 915-928. DOI: https://doi.org/10.1002/ar. 21381

Ginot, S., Claude, J., and Hautier, L. (2018). One skull to rule them all? Descriptive and comparative anatomy of the masticatory apparatus in five mice species based on traditional and digital dissections. Journal of Morphology. https://doi.org/10.1002/jmor.20845 